\title{
Pulsed radiofrequency treatment of articular branches of femoral and obturator nerves for chronic hip pain
}

\author{
Cien-Leong Chye' \\ Cheng-Loong Liang' \\ Kang Lu' \\ Ya-Wen Chen ${ }^{2,3}$ \\ Po-Chou Liliang' \\ 'Department of Neurosurgery, \\ E-Da Hospital, I-Shou University, \\ ${ }^{2}$ Department of Nursing, I-Shou \\ University, ${ }^{3}$ School of Nursing, \\ Kaohsiung Medical University, \\ Kaohsiung, Taiwan
}

\author{
This article was published in the following Dove Press journal: \\ Clinical Interventions in Aging \\ 16 March 2015 \\ Number of times this article has been viewed
}

Correspondence: Po-Chou Liliang Department of Neurosurgery, E-Da Hospital, I-Shou University, Number I, E-Da Road, Jiau-Shu Tsuen, Yan-Chau District, Kaohsiung City, 824, Taiwan Tel +88676I5 00II

Fax +88676150982

Email edI00I72@edah.org.tw
Purpose: Chronic hip pain is a common symptom experienced by many people. Often, surgery is not an option for patients with multiple comorbidities, and conventional drugs either have many side effects or are ineffective. Pulsed radiofrequency (PRF) is a new method in the treatment of pain. We attempt to compare the efficacy of PRF relative to conservative management for chronic hip pain.

Patients and methods: Between August 2011 and July 2013, 29 patients with chronic hip pain were divided into two groups (PRF and conservative treatment) according to consent or refusal to undergo PRF procedure. Fifteen patients received PRF of the articular branches of the femoral and obturator nerves, and 14 patients received conservative treatment. Visual analog scale (VAS), Oxford hip scores (OHS), and pain medications were used for outcome measurement before treatment and at 1 week, 4 weeks, and 12 weeks after treatment.

Results: At 1 week, 4 weeks, and 12 weeks after treatment initiation, improvements in VAS were significantly greater with PRF. Improvements in OHS were significantly greater in the PRF group at 1 week, 4 weeks, and 12 weeks. Patients in the PRF group also used less pain medications. Eight subjects in the conservative treatment group switched to the PRF group after 12 weeks, and six of them had $>50 \%$ improvement.

Conclusion: When compared with conservative treatment, PRF of the articular branches of the femoral and obturator nerves offers greater pain relief for chronic hip pain and can augment physical functioning.

Keywords: pulsed radiofrequency, obturator and femoral nerves, hip joint pain, osteoarthritis

\section{Introduction}

Chronic hip pain is a common symptom experienced by many people. This condition can range from mild discomfort to severe pain that limits activities of daily living. Conservative management of hip pain includes paracetamol, nonsteroidal antiinflammatory drugs (NSAIDs), narcotics, and physical modalities. ${ }^{1,2}$ Patients who fail to respond to conservative treatment usually undergo surgery. Often, surgery is not an option for patients with multiple comorbidities and conventional drugs either have many side effects or are ineffective. ${ }^{3,4}$ Percutaneous pulsed radiofrequency $(\mathrm{PRF})^{1}$ or conventional radiofrequency $(\mathrm{CRF})^{2-6}$ of the articular branches of the obturator and femoral nerves is a novel alternative treatment for hip pain that has been previously reported in literature. However, the efficacy of PRF or CRF in hip pain is not well established because comparative studies with conservative management have not been conducted. There are only anecdotal evidences in the literatures. ${ }^{1-6}$ 
PRF is a new method in RF treatment of pain. It is a nonneurolytic lesioning method for pain relief and can relieve pain without evidence of neural damage. ${ }^{7,8}$ In the present prospective, nonrandomized, open-label study, we attempt to compare the efficacy of PRF relative to conservative management for chronic hip pain.

\section{Materials and methods} Patients and eligibility

This comparative study was approved by the local institutional review board. Patients suffering from chronic hip pain for $>3$ months with radiographic osteoarthritis of the hip (Tönnis grades I and II) were approached for this study. Patients presented with pain on a range of motions, groin and thigh pain, and limitation of range of motion, especially internal rotation. Patients also underwent various combinations of imaging studies (plain films, computed tomography, or magnetic resonance imaging) to diagnose and exclude other causes of pain originating from spine, sacroiliac joint, or other sources. Between August 2011 and July 2013, 29 patients with chronic osteoarthritic hip pain were recruited.

\section{Exclusion criteria}

Exclusion criteria comprised refusal to participate, extrinsic source of hip pain (eg, lumbar radiculopathy), pain related to bony fracture, avascular necrosis of hip, postsurgical pain, anticoagulation therapy, local infection over buttock and hip, systemic sepsis, allergy to local anesthetics, psychiatric illness, and inability to comprehend pain scoring. Subjects with ongoing litigation and secondary gain were also excluded. Treatment options and potential hazards were discussed with patients. Informed consent was obtained.

\section{Study protocol}

The patients were divided into two groups (PRF and conservative treatment) according to consent or refusal to undergo PRF procedure. Fifteen patients were offered PRF. Fourteen patients who declined PRF because of the possibility of PRF complications were managed conservatively. These patients received exercise programs and medications, including paracetamol, NSAIDs, and/or narcotic drugs for chronic hip pain. Patients who declined PRF were evaluated longitudinally and served as controls. In the PRF group, patients received the PRF procedure and exercise programs. Pain medications were allowed if PRF procedures did not decrease chronic hip pain. Patients who received conservative treatment but who still had severe pain could receive PRF procedure after 12 weeks' treatment if they wanted to cross over. Any patient could leave the study without explanation of their motivation at any moment.

\section{Intervention}

The techniques for radiofrequency (RF) lesioning of the articular branches of the femoral and obturator nerves are described elsewhere. ${ }^{1,9,10}$ PRF was performed under strict sterile conditions in an operating room. Each patient was placed in a supine position, and the skin overlying the operation area was prepared and draped. A standard RF lesion generator (Neurotherm JK 25T) was used for the whole procedure. After administration of local anesthesia ( $2 \%$ lidocaine), a 22-gauge 10 -mm active tip RF cannula (NeuroTherm) $10 \mathrm{~cm}$ in length was inserted and advanced toward the articular branches of the obturator and femoral nerves (Figure 1). Denervation of the sensory branches of the obturator and femoral nerves using PRF was performed in all the patients. Proper localization of the nerve was achieved by sensory stimulation. Sensory stimulation covering the painful region was obtained $(50 \mathrm{~Hz} ; 1 \mathrm{~ms}$ pulse width; $<0.6 \mathrm{~V})$. The impedance ranged from $170 \mathrm{ohms}$ to $350 \mathrm{ohms}$. Two PRF cycles of 180 seconds were performed after localization. The RF current was delivered at a width of $20 \mathrm{~ms}$ at $45 \mathrm{~V}$. The tip temperature was no more than $42^{\circ} \mathrm{C}$. Patients were observed for 30 minutes after the PRF procedure. If no significant complications (including pain, numbness, bleeding, hematoma, and leg weakness) were observed, the patient was discharged.

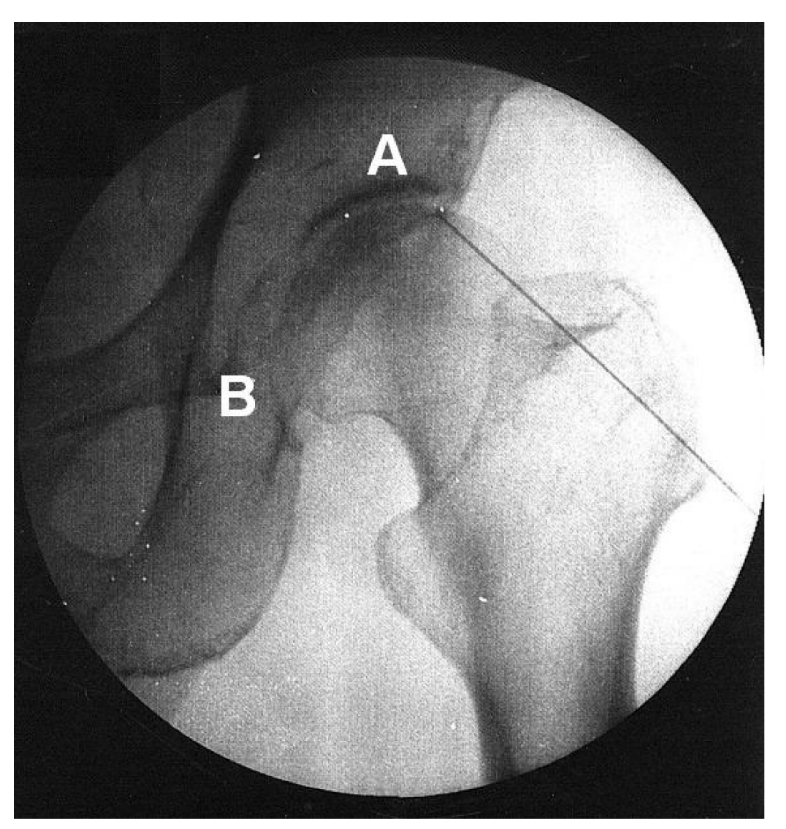

Figure I Fluoroscopic image showing radiofrequency cannula toward the articular branches of the femoral nerve $(\mathbf{A})$ and the obturator nerve (B). 


\section{Outcome measurement}

Patients were followed up in the outpatient department after discharge. Pain intensity, physical functioning, and pain medication were assessed before treatment, at 1 week, at 4 weeks, and at 12 weeks after treatment. All patients were independently assessed by a nurse who was blinded to the treatment undertaken. Pain intensity was recorded by using a visual analog scale (VAS) ranging from zero (no pain) to ten (extremely severe pain). Pain and physical functioning of the hip were also evaluated by the Oxford hip scores (OHS) questionnaire, a self-reported 12 -item questionnaire. ${ }^{11,12}$ The range of scores is from 12 to 60 , with a higher score indicating worsening pain and poor function. Pain medication after treatment was assessed using a scale ranging from 0 to 4 ( $0=$ no medication; $1=$ use of paracetamol; $2=$ use of NSAIDs; $3=$ use of opiate derivatives; $4=$ routinely scheduled opiate derivatives).

\section{Statistical analysis}

Descriptive statistics were used to characterize the patients. Pre- and posttreatment ranges, means, and standard deviations were calculated. Friedman test was performed to compare the differences within groups across time. Differences between groups were evaluated using $\chi^{2}$, Fisher's exact test, or Mann-Whitney $U$-test, as appropriate. Comparisons were performed with Bonferroni correction. We used two-tailed tests of significance $(P<0.05)$. Data were analyzed using SPSS version 12.0 (SPSS Inc, Chicago, IL, USA).

\section{Results}

The present study recruited 29 patients with chronic hip pain. Fifteen patients received PRF, while 14 received conservative treatment. Patients in both groups were comparable in terms of demographic and baseline characteristics, with no significant differences between the two groups (Tables 1 and 2).

Table I Demographics of both study groups

\begin{tabular}{|c|c|c|c|}
\hline \multirow[t]{2}{*}{ Characteristics } & \multirow{2}{*}{$\begin{array}{l}\text { PRF } \\
(\mathrm{N}=15) \\
\text { Mean (SD) }\end{array}$} & \multirow{2}{*}{$\begin{array}{l}\text { Conservative } \\
(\mathrm{N}=14) \\
\text { Mean (SD) }\end{array}$} & \multirow[t]{2}{*}{$P$} \\
\hline & & & \\
\hline Age (years) & 65.53 (II.7) & 67.71 (1I.8) & NS \\
\hline \multicolumn{3}{|l|}{ Sex } & NS \\
\hline Female (\%) & $9(60.0)$ & $10(7 \mathrm{I} .4)$ & \\
\hline Male (\%) & $6(40.0)$ & $4(28.6)$ & \\
\hline \multicolumn{3}{|l|}{ Location } & NS \\
\hline Left (\%) & $6(40.0)$ & $3(2 \mid .4)$ & \\
\hline Right (\%) & $7(46.7)$ & $6(42.9)$ & \\
\hline Both (\%) & $2(13.3)$ & $5(35.7)$ & \\
\hline
\end{tabular}

Abbreviations: NS, not significant; PRF, pulsed radiofrequency; SD, standard deviation.
Table 2 Comparison of outcomes between both study groups

\begin{tabular}{|c|c|c|c|}
\hline \multirow[t]{2}{*}{ Characteristics } & \multirow{2}{*}{$\begin{array}{l}\text { PRF } \\
(\mathrm{N}=15) \\
\text { Mean } \pm \text { SD }\end{array}$} & \multirow{2}{*}{$\begin{array}{l}\text { Conservative } \\
(\mathbf{N}=14) \\
\text { Mean } \pm \text { SD }\end{array}$} & \multirow[t]{2}{*}{$P$} \\
\hline & & & \\
\hline \multicolumn{4}{|l|}{ VAS scores } \\
\hline Baseline & $6.7 \pm 0.6$ & $6.7 \pm 0.8$ & 0.981 \\
\hline I week & $2.2 \pm 1.5$ & $5.1 \pm 1.0$ & 0.001 \\
\hline Score change & $-4.5 \pm 1.4$ & $-1.6 \pm 0.9$ & 0.001 \\
\hline 4 weeks & $2.4 \pm I .4$ & $5.1 \pm 1.7$ & 0.001 \\
\hline Score change & $-4.3 \pm 1.4$ & $-1.6 \pm 1.3$ & 0.002 \\
\hline 12 weeks & $3.0 \pm 1.8$ & $4.7 \pm 2.0$ & 0.017 \\
\hline Score change & $-3.7 \pm 2.0$ & $-2.0 \pm 1.7$ & 0.030 \\
\hline \multicolumn{4}{|c|}{ Oxford hip scores } \\
\hline Baseline & $28.2 \pm 5.2$ & $27.9 \pm 3.9$ & 0.93 \\
\hline I week & $18.7 \pm 4.9$ & $26.2 \pm 4.6$ & 0.001 \\
\hline Score change & $9.5 \pm 1.5$ & $1.7 \pm 3.3$ & 0.001 \\
\hline 4 weeks & $19.8 \pm 4.3$ & $26.2 \pm 4.9$ & 0.001 \\
\hline Score change & $8.4 \pm 3.4$ & $1.7 \pm 3.2$ & 0.001 \\
\hline 12 weeks & $21.1 \pm 5.1$ & $25.8 \pm 5.9$ & 0.04 \\
\hline Score change & $7.1 \pm 4.7$ & $2.1 \pm 4.0$ & 0.01 \\
\hline \multicolumn{4}{|l|}{ Pain medications } \\
\hline I week & $1.4 \pm 1.1$ & $2.4 \pm 0.5$ & 0.010 \\
\hline 4 weeks & $1.5 \pm 1.0$ & $2.4 \pm 0.4$ & 0.007 \\
\hline 12 weeks & $1.4 \pm 1.1$ & $2.3 \pm 0.5$ & 0.010 \\
\hline
\end{tabular}

Abbreviations: PRF, pulsed radiofrequency; SD, standard deviation; VAS, visual analog scale.

The flow diagram demonstrates study recruitment, allocation, and follow-up (Figure 2).

Table 2 and Figures 3-4 present outcome data for the patients in both groups. After 1 week, changes in VAS scores $(P<0.001)$ and revised OHS values $(P<0.001)$ were significantly greater in the PRF group than in the conservative group. These changes remained significantly greater at 4 weeks and 12 weeks. The VAS scores in the PRF group were significantly lower than those in the conservative group at 1 week $(P<0.001), 4$ weeks $(P<0.001)$, and 12 weeks $(P=0.017)$. The OHS values were also lower in the PRF group at 1 week $(P<0.001), 4$ weeks $(P<0.001)$, and 12 weeks $(P=0.04)$.

Friedman analysis indicated that for both groups, there were significant differences $(P<0.001)$ in the VAS scores after treatment. However, the differences in OHS were only significant in the PRF group $(P<0.001)$. No significant differences in OHS values were found after treatment in the conservative group. Thus, both PRF and conservative therapy could provide pain reduction. However, only PRF could provide improvement in the physical functioning of hip pain patients.

The pain medication scores were significantly lower in the PRF group at 1 week $(P=0.01), 4$ weeks $(P=0.007)$, and 


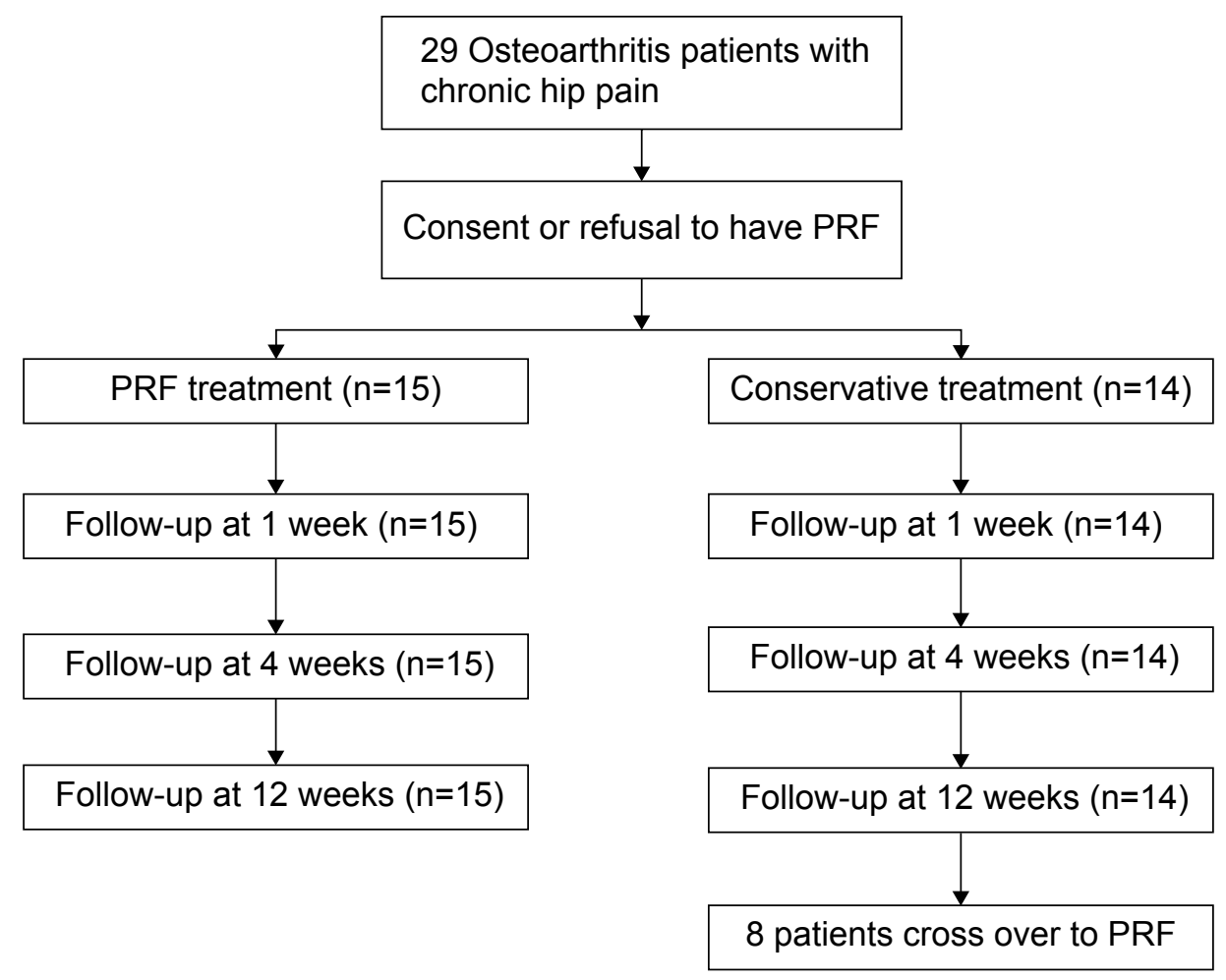

Figure 2 CONSORT diagram for patient recruitment, allocation, and follow-up.

Abbreviations: CONSORT, Consolidated Standards of Reporting Trials; PRF, pulsed radiofrequency.

12 weeks $(P=0.01)$. Thus, PRF could provide not only better effect (1-12 weeks) in terms of pain relief and physical functioning improvement but also less medication requirement.

\section{Crossover}

Eight participants in the control group switched to the PRF treatment group after 12 weeks. Six $(75 \%)$ of them had an

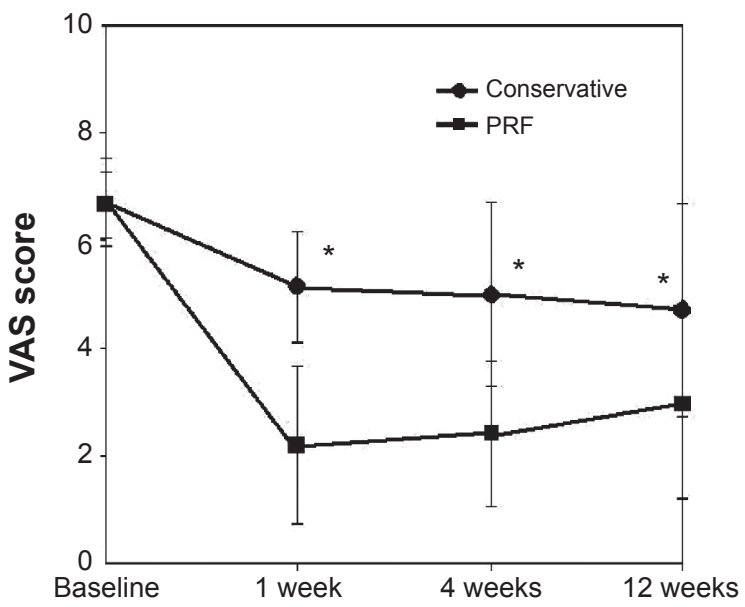

Figure 3 Longitudinal changes in mean $( \pm S D)$ VAS scores.

Notes: Patients treated by PRF are compared with patients treated conservatively. Asterisk indicates $P<0.05$ for between-group comparisons.

Abbreviations: PRF, pulsed radiofrequency; SD, standard deviation; VAS, visual analog scale. improvement of $>50 \%$ with the pain, whereas two patients (25\%) had no improvement.

\section{Complications}

Patients received assessment of adverse events at 1 week, 4 weeks, and 12 weeks after the procedure. No major complications related with PRF were observed, except for one

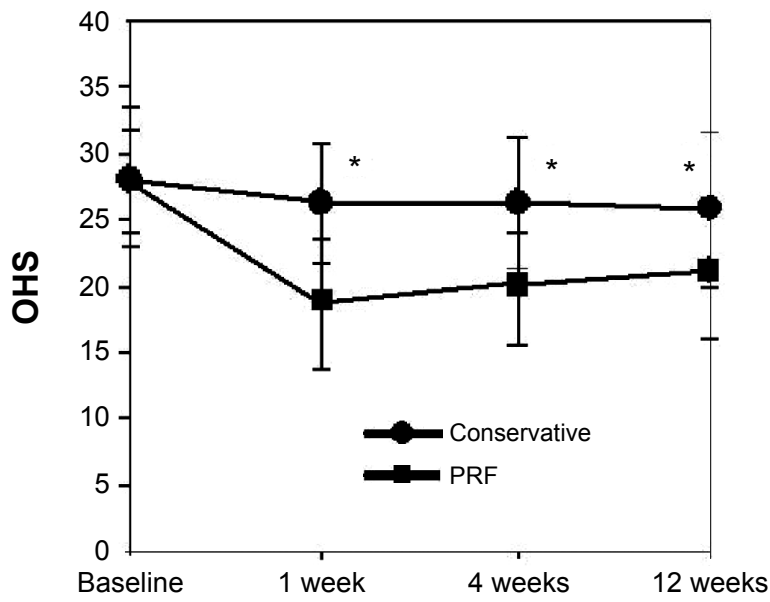

Figure 4 Longitudinal changes in mean $( \pm S D)$ Oxford hip scores.

Notes: Patients treated by PRF are compared with patients treated conservatively. Asterisk indicates $P<0.05$ for between-group comparisons.

Abbreviations: OHS, Oxford hip scores; PRF, pulsed radiofrequency; SD, standard deviation. 
subcutaneous hematoma related to RF needle puncture, which presented for 1 week.

\section{Discussion}

The present study compared PRF with conservative treatment and demonstrates that at 1 week, 4 weeks, and 12 weeks after treatment initiation, improvements in pain are significantly greater with PRF. Improvements of OHS were significantly greater in the PRF group at 1 week, 4 weeks, and 12 weeks. Patients in the PRF group also used less medication. PRF provides prompt pain relief, rapid improvements in physical functioning, and a decline in pain medication use.

The sensory nerves supplying the hip joint include the articular branches of the obturator, femoral, and superior gluteal nerves from the sciatic nerve. ${ }^{10}$ Major symptoms of chronic hip pain include groin, thigh, and trochanteric pain. Groin and medial thigh pain often arises from the articular branches of the obturator nerve, whereas trochanteric and lateral thigh pain arises from the articular branches of the femoral nerve. ${ }^{1}$ In the present study, all the subjects received PRF of both articular branches of the femoral and obturator nerves. Lesioning on both nerves provides better pain relief than selecting one nerve according to pain location.

Anesthetic obturator or femoral nerve blocks have been used to eliminate arthritic hip pain. Two studies using nerve blocks of the obturator nerve or femoral nerve revealed that each nerve block could only alleviate pain in the arthritic hip for 2 weeks, but the pain subsequently increased to preblock levels. ${ }^{13,14}$ Flanagan et $\mathrm{al}^{15}$ found that intra-articular injection of local anesthetic alone or local anesthetic plus steroid provided short-term pain relief, but no long-term benefit. Anesthetic obturator/femoral nerve blocks and intra-articular blocks were effective for hip pain, but long-term benefits were not observed. The results support the hypothesis that the articular branches of the femoral and obturator nerves are important mediators of hip pain.

To obtain longer effects, Kawaguchi et $\mathrm{al}^{2}$ performed CRF ablation of sensory branches of the obturator and femoral nerves in 14 patients and found significant pain relief (at least $50 \%$ ) in 12 patients. The duration of pain relief was 1-11 months (mean: 4.2 months). In the past 10 years, the use of CRF for chronic hip pain has become popular. Several studies have reported similar results and pain relief for several months. ${ }^{2-6} \mathrm{CRF}$ in which a constant high temperature $\left(60^{\circ} \mathrm{C}-80^{\circ} \mathrm{C}\right)$ is applied to target tissue reduces chronic pain by nerve ablation. It can provide long-lasting pain relief; however, irreversible damage to neural tissue could occur. ${ }^{16}$ Although CRF has been widely used for spinal pain, some have questioned the utility of thermal lesioning in the presence of neuropathic pain as a result of nerve damage. ${ }^{17,18}$ Numbness of the hip related with thermal coagulation during $\mathrm{CRF}$ and subcutaneous hematoma at the puncture site were the complications. ${ }^{3,4}$

PRF is a new method in RF treatment of pain. Although the mechanism of action is not completely understood, some reports support its long-term efficacy and safety in pain relief. ${ }^{7,8} \mathrm{Wu}$ et $\mathrm{al}^{1}$ reported PRF of the articular branches of the obturator and femoral nerves in 2 patients with chronic hip pain and demonstrated at least $50 \%$ pain relief for 3.5 months. In the present study, PRF provides better pain relief and rapid improvements in physical functioning than conservative treatment. The only complication was subcutaneous hematoma in one patient related to needle puncture. Eight subjects in the conservative treatment group finally received PRF treatment after 12 weeks; and of these, six got $>50 \%$ pain relief.

Exactly how the PRF acts to produce a resolution of pain remains unclear. Many experimental studies have attempted to elucidate the exact analgesic mechanism of PRF. PRF involves short bursts of RF energy applied to nervous tissue. Unlike CRF ablation, it produces little tissue destruction but lasting inhibition of evoked synaptic activity. ${ }^{19} \mathrm{PRF}$ induces cellular distress, as measured by expression of neuron activation transcription factor-3, and both $\mathrm{C}$ and A delta sensory fibers appear to be selectively targeted by it. ${ }^{20}$ Ultrastructural changes include abnormal membranes and mitochondria morphology and disrupted and disorganized microfilaments and microtubules. ${ }^{21}$ These changes are greater in $\mathrm{C}$ fibers than in A-beta fibers. Some studies have examined electrical fields on upregulation of immediate early gene and c-Fos. ${ }^{22,23} \mathrm{PRF}$ lesioning to the rat dorsal root ganglion was associated with a significant increase of c-Fos immunoreactive cells in the dorsal horn of the spinal cord. ${ }^{22,23}$ The expression of the $c$-fos gene encourages the formation of preprodynorphin, which is the second RNA messenger. This results in an increased production of endorphin that modulates analgesic action, which may cause a prolonged analgesic effect. ${ }^{24}$

The present study has some limitations. A nonrandomized study with patients recruited according to consent or refusal to have PRF could have some self-selection bias.

Participants agreeing to undergo the PRF procedure are more likely to believe in the benefit of the procedure, and this may significantly affect results. However, the nonsignificance of the statistical results in the pretreatment variables and the baseline VAS and OHS (Tables 1 and 2) values argue against this concern. Twelve weeks' observation is not enough for 
long-term pain relief. However, the observation period for anesthesia for hip pain using PRF is no more than 4 months. ${ }^{1}$ Further studies are needed for elucidating the long-term efficacy and safety of PRF. The present study also has its strengths. Although several studies have reported that PRF and CRF on sensory branches of the obturator and femoral nerves are effective for chronic hip pain, ${ }^{1-6}$ none used a control group.

\section{Conclusion}

PRF of the articular branches of the femoral and obturator nerves offers a treatment option with good outcomes for patients suffering from chronic hip pain. When compared with conservative treatment, it offers greater pain relief and can augment physical functioning. Although this study produced promising results, caution is advised in drawing conclusions from this single study. Controlled, randomized investigations with longer observation periods are necessary to further clarify the role of PRF in the treatment of chronic hip pain.

\section{Acknowledgment}

This work was supported by research grants from I-Shou University Grant ISU 100-04-11 to P-CL.

\section{Disclosure}

The authors report no conflicts of interest in this work.

\section{References}

1. Wu H, Groner J. Pulsed radiofrequency treatment of articular branches of the obturator and femoral nerves for management of hip joint pain. Pain Pract. 2007;7:341-344.

2. Kawaguchi M, Hashizume K, Iwata T, Furuya H. Percutaneous radiofrequency lesioning of sensory branches of the obturator and femoral nerves for the treatment of hip joint pain. Reg Anesth Pain Med. 2001; 26:576-581.

3. Malik A, Simopolous T, Elkersh M, Aner M, Bajwa ZH. Percutaneous radiofrequency lesioning of sensory branches of the obturator and femoral nerves for the treatment of non-operable hip pain. Pain Physician. 2003; 6:499-502.

4. Rivera F, Mariconda C, Annaratone G. Percutaneous radiofrequency denervation in patients with contraindications for total hip arthroplasty. Orthopedics. 2012;35:e302-e305.

5. Okada K. New approach to the pain of the hip joint. Pain Res. 1993;8: 125-135.

6. Fukui S, Nosaka S. Successful relief of hip joint pain by percutaneous radiofrequency nerve thermocoagulation in a patient with contraindications for hip arthroplasty. $J$ Anesth. 2001;15:173-175.

Clinical Interventions in Aging

\section{Publish your work in this journal}

Clinical Interventions in Aging is an international, peer-reviewed journal focusing on evidence-based reports on the value or lack thereof of treatments intended to prevent or delay the onset of maladaptive correlates of aging in human beings. This journal is indexed on PubMed Central, MedLine,
7. Munglani R. The longer term effect of pulsed radiofrequency for neuropathic pain. Pain. 1999;80:437-439.

8. Vallejo R, Benyamin RM, Kramer J, Stanton G, Joseph NJ. Pulsed radiofrequency denervation for the treatment of sacroiliac joint syndrome. Pain Med. 2006;7:429-434.

9. Locher S, Burmeister H, Böhlen T, et al. Radiological anatomy of the obturator nerve and its articular branches: basis to develop a method of radiofrequency denervation for hip joint pain. Pain Med. 2008;9: 291-298.

10. Birnbaum K, Prescher A, Hessler S, Heller KD. The sensory innervation of the hip joint - an anatomical study. Surg Radiol Anat. 1997;19: 371-375.

11. Dawson J, Carr A, Murray D. Questionnaire on the perceptions of patients about total hip replacement. J Bone Joint Surg. 1996;78-B:185.

12. Kalairajah Y, Azurza K, Hulme C, Molloy S, Drabu KJ. Health outcome measures in the evaluation of total hip arthroplasties - a comparison between the Harris hip score and the Oxford hip score. J Arthroplasty. 2005;20:1037-1041.

13. James CD, Little TF. Regional hip blockade. Anaesthesia. 1976;31: 1060-1067.

14. Edmonds-Seal J, Turner A, Khodadadeh S, Bader DL, Fuller DJ. Regional hip blockade in osteoarthrosis. Anaesthesia. 1982;37:147-151.

15. Flanagan J, Thomas T, Casale F, Desai K. Intraarticular injection for pain relief in patients awaiting hip replacement. Ann R Coll Surg Engl. 1988;70:156-157.

16. Abbott Z, Smuck M, Haig A, Sagher O. Irreversible spinal nerve injury from dorsal ramus radiofrequency neurotomy: a case report. Arch Phys Med Rehabil. 2007;88:e1350-e1352.

17. McDonald GJ, Lord SM, Bogduk N. Long-term follow-up of patients treated with cervical radiofrequency neurotomy for chronic neck pain. Neurosurgery. 1999;45:61-68.

18. Zakrzewska JM, Jassim S, Bulman JS. A prospective, longitudinal study on patients with trigeminal neuralgia who underwent radiofrequency thrermocoagulation of the gasserian ganglion. Pain. 1999;79:51-58.

19. Cahana A, Vutskits L, Muller D. Acute differential modulation of synaptic transmission and cell survival during exposure to pulsed and continuous radiofrequency energy. J Pain. 2003;4:197-202.

20. Hamann W, Abou-Sherif S, Thompson S, Hall S. Pulsed radiofrequency applied to dorsal root ganglia causes a selective increase in ATF3 in small neurons. Eur J Pain. 2006;10:171-176.

21. Erdine S, Bilir A, Cosman ER, Cosman ER. Ultrastructural changes in axons following exposure to pulsed radiofrequency fields. Pain Pract. 2009;9:407-417.

22. Haguichi Y, Nashold BS, Sluijter M, Cosman E, Pearlstein RD. Exposure of the dorsal root ganglion in rats to pulsed radiofrequency currents activates dorsal horn lamina I and II neurons. Neurosurgery. 2002;50:850-855.

23. Van Zundert J, de Louw AJ, Joosten EA, et al. Pulsed and continuous radiofrequency current adjacent to the cervical dorsal root ganglion of the rat induces late cellular activity in the dorsal horn. Anesthesiology. 2005;102:125-131.

24. Hunter JC, Woodburn VL, Durieux C, Pettersson EK, Poat JA, Hughes J. c-fos antisense oligodeoxynucleotide increases formalininduced nociception and regulates preprodynorphin expression. Neuroscience. 1995;65:485-492.

CAS, Scopus and the Elsevier Bibliographic databases. The manuscript management system is completely online and includes a very quick and fair peer-review system, which is all easy to use. Visit http://www.dovepress. com/testimonials.php to read real quotes from published authors. 